\title{
IMPROVEjob - Participatory intervention to improve job satisfaction of general practice teams: a model for structural and behavioural prevention in small and medium-sized enterprises - a study protocol of a cluster-randomised controlled trial
}

Birgitta M. Weltermann ${ }^{1,2^{*}} \mathbb{D}$, Christine Kersting ${ }^{2}$, Claudia Pieper ${ }^{3}$, Tanja Seifried-Dübon ${ }^{4}$, Annegret Dreher $^{1}$, Karen Linden ${ }^{1}$, Esther Rind ${ }^{5}$, Claudia Ose ${ }^{6}$, Karl-Heinz Jöckel $^{3,6}$, Florian Junne $^{4}$, Brigitte Werners ${ }^{7}$, Verena Schroeder ${ }^{6}$, Jean-Marie Bois ${ }^{6}$, Achim Siegel $^{5}$, Anika Thielmann ${ }^{1}$, Monika A. Rieger ${ }^{5}$, Stefanie Kasten ${ }^{1}$ and on behalf of the IMPROVEjob consortium

\begin{abstract}
Background: Perceived high chronic stress is twice as prevalent among German general practitioners (GPs) and non-physician medical staff compared to the general population. The reasons are multi-factorial and include patient, practice, healthcare system and societal factors, such as multi-morbidity, the diversity of populations and innovations in medical care. Also, practice-related factors, like stressful patient-staff interactions, poor process management of waiting times and lack of leadership, play a role. This publicly funded study evaluates the effectiveness of the newly developed participatory, interdisciplinary, and multimodal IMPROVEjob intervention on improving job satisfaction among general practice personnel. The intervention aims at structural stress prevention with regard to working conditions and behavioural stress prevention for leaders and other practice personnel.

* Correspondence: birgitta.weltermann@ukbonn.de

'Institute of General Practice and Family Medicine, University Hospital Bonn, University of Bonn, Venusberg-Campus 1, 53127 Bonn, Germany

${ }^{2}$ Institute for General Medicine, University Hospital Essen, University of Duisburg-Essen, Hufelandstr 55, 45122 Essen, Germany

Full list of author information is available at the end of the article

(c) The Author(s). 2020, corrected publication 2020. Open Access This article is licensed under a Creative Commons Attribution 4.0 International License, which permits use, sharing, adaptation, distribution and reproduction in any medium or format, as long as you give appropriate credit to the original author(s) and the source, provide a link to the Creative Commons licence, and indicate if changes were made. The images or other third party material in this article are included in the article's Creative Commons licence, unless indicated otherwise in a credit line to the material. If material is not included in the article's Creative Commons licence and your intended use is not permitted by statutory regulation or exceeds the permitted use, you will need to obtain permission directly from the copyright holder. To view a copy of this licence, visit http://creativecommons.org/ licenses/by/4.0/. The Creative Commons Public Domain Dedication waiver (http://creativecommons.org/publicdomain/zero/1. 0/) applies to the data made available in this article, unless otherwise stated in a credit line to the data. 
(Continued from previous page)

Methods: In this cluster-randomised controlled trial, a total of 56 general practices will be assigned to either (1) participation in the IMPROVEjob intervention or (2) the waiting-list control group. The IMPROVEjob intervention consists of the following elements: three workshops, a toolbox with supplemental material and an implementation period with regular contact to so-called IMPROVEjob facilitators. The first workshop, addressing leadership issues, is designed for physicians with leadership responsibilities only. The two subsequent workshops target all GP and nonphysician personnel; they address issues of communication (with patients and within the team), self-care and teamcare and practice organisation. During the 9-month implementation period, practices will be contacted by IMPROVEjob facilitators to enhance motivation. Additionally, the practices will have access to the toolbox materials online. All participants will complete questionnaires at baseline and follow up. The primary outcome is the change in job satisfaction as measured by the respective scale of the validated German version of the Copenhagen Psychosocial Questionnaire (COPSOQ, version 2018). Secondary outcomes obtained by questionnaires and qualitatively - by facilitators comprise psychosocial working conditions including leadership aspects, expectations and experiences of the workshops, team and individual efforts and organisational changes.

Discussion: It is hypothesised that participation in the IMPROVEjob intervention will improve job satisfaction and thus constitute a structural and behavioural prevention strategy for the promotion of psychological wellbeing of personnel in general practices and prospectively in other small and medium sized enterprises.

Trial registration: German Clinical Trials Register: DRKS00012677. Registered on 16 October 2019. Retrospectively, https://www.drks.de/drks_web/navigate.do?navigationld=trial. HTML\&TRIAL_ID = DRKS00012677.

Keywords: Job satisfaction, Perceived psychological stress, Primary care, General practices, Participatory intervention, Psychological well-being, Effectiveness, Leadership, Structural prevention, Behavioural prevention

\section{Contributions to the literature}

This study will contribute as follows:

1. Few studies have evaluated participatory intervention strategies to improve job satisfaction in small and medium sized enterprises

2. This study protocol describes a cluster randomised trial aiming to improve job satisfaction in general practice personnel

3. The intervention aims at activating the target group

4. The study comprises behavioural and structural prevention strategies

5. Issues of leadership, communication and work organisation in practices are addressed.

\section{Background}

Poor job satisfaction is an ongoing issue across many job domains worldwide $[1,2]$. Due to the shortage of physicians in primary care in many countries, increased research efforts are directed to how to maintain and improve job satisfaction in this workforce [3-5]. Studies in various general practice populations in Europe and beyond showed that job satisfaction is profoundly influenced by work-related factors [5-7]. Factors that are known to decrease job satisfaction include too many working hours, administrative burdens, inadequate income, heavy workload, and lack of time and recognition [7]. Persistently low job satisfaction is related not only to chronic stress, burnout, depression, early retirement and other indicators of physicians' health, but is also linked to less satisfactory patient outcomes [8-15]. A study by Viehmann et al. showed that physicians and nonphysician personnel in general practices are twice as likely to experience high chronic stress compared to the general population [10]. In the same population, physicians in group practices had a higher rate of burnout than those from single practices, with young, part-time, female physicians employed there having the highest burnout rate, even when compared to group practice owners [16]. Various reasons for high strain were identified; key factors were quality of leadership, difficult patient-encounters and practice organisation $[10,17,18]$.

Various approaches to improving the mental wellbeing of healthcare workers have been evaluated [19, 20]. Many approaches address individual behaviour such as stress management, meditation, or training in self-care $[21,22]$. However, based on the European principles of occupational health and safety, interventions should first target the work environment of individuals and address behavioural prevention thereafter [23]. A review by Montano et al. about the effectiveness of organisationrelated interventions showed that health-promoting effects were achieved among employees when interventions simultaneously focused on work equipment, work processes and working conditions [24].

Having identified lack of leadership, difficult patientencounters and practice organisation as problems in German general practices $[10,18]$, the IMPROVEjob 
intervention was developed under the leadership of a family medicine physician and scientist, following an interdisciplinary and participatory approach: experts from the fields of general practice and family medicine, occupational and psychosomatic medicine, operations research, health promotion and epidemiology provided input into the various areas; a research support group with GPs and practice assistants was repeatedly asked for input and feedback to ensure that the intervention is tailored to the needs and capacities of general practice teams. The intervention focuses on reducing workrelated psychological stress, to increase job satisfaction. It consists of three workshops (i.e. a leadership workshop for physicians with leadership responsibilities and two workshops for the entire practice team), a toolbox and so-called IMPROVEjob facilitators to support implementation. Learning contents for participants focus on issues relating to leadership, communication and work processes. The main aim of this cluster-randomised controlled trial (cRCT) is to investigate whether the IMPROVEjob intervention increases job satisfaction amongst general practice personnel.

\section{Methods/design}

\section{Study design}

This cRCT evaluates the effectiveness of the IMPROVEjob intervention in improving job satisfaction (primary outcome) among practice personnel. Randomisation will take place at practice level, i.e. all personnel in the practice will be assigned either to the intervention or to the control group. The study will be conducted according to the waiting-list control principle, i.e. practices of the intervention group will receive the IMPROVEjob intervention after the baseline data collection; the control group will receive the workshops after completion of the study. For details see Fig. 1.

\section{Participants and recruitment}

The study will be conducted in general practices of the North Rhine region in Germany. Urban and rural medical practices are selected to ensure better generalisation of the results. Practices will be drawn as random samples from an official list of registered general practice physicians of the Association of Statutory Health Insurance Physicians of North Rhine (in German, Kassenärztliche Vereinigung Nordrhein) in these selected areas and from a list of teaching practices of regional universities. We previously showed that teaching practices are typically easier to recruit and do not differ from non-teaching practices with regard to health service characteristics [25]. We therefore aimed for an approximately equal distribution of teaching and non-teaching practices in the final sample.

The practices will be contacted by the Institute of General Practice and Family Medicine of the University of Bonn. Depending on available contact details, practices will be sent invitation letters by mail, fax and/or email, each of which include participant information and an informed consent form for the practice owner. Practices will then be contacted by phone to provide additional study information. As soon as the practice owner has given written consent, a visit by a study nurse from the Center for Clinical Trials in Essen (in German, ZKSE, Zentrum für klinische Studien Essen), is scheduled. During this visit, the study nurse will obtain informed consent from each participating team member, distribute and collect the baseline questionnaire data, and complete an observational occupational health and safety form. In the consent form, participants are informed that they are free to discontinue study participation at any time. Questionnaires will be checked for completeness of data. To promote participant retention and to prevent loss to follow up, each participant will receive $50 €$ after the intervention. In addition, IMPROVEjob facilitators will motivate participants to complete the study.

\section{Inclusion and exclusion criteria}

Practices will be included if at least one practice physician is registered as a GP with the Association of

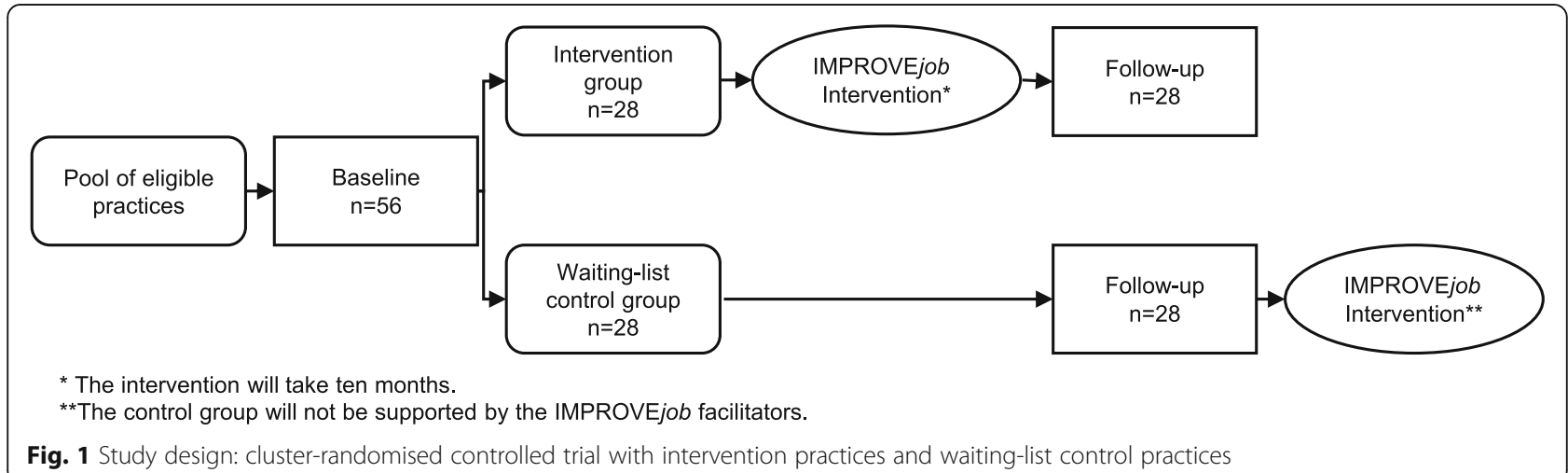

Fig. 1 Study design: cluster-randomised controlled trial with intervention practices and waiting-list control practices 
Statutory Health Insurance Physicians of North Rhine with or without teaching obligations. Practice teams are eligible for participation if at least one physician with leadership responsibilities and at least one practice assistant provide informed consent for study participation. Physicians with leadership responsibilities include physician practice owners and employed practice physicians with respective duties. Our aim is to recruit all members of a practice team including employed physicians and practice assistants in training.

Exclusion criteria are a foreseeable special situation that might interfere with the completion of the study, such as practice relocation or retirement of the practice owner; practices that are not primarily involved in primary care (e.g. predominantly providing psychotherapy or pain therapy); and practices that participated in the development of the IMPROVEjob intervention or in the feasibility study of the intervention.

\section{Randomisation}

General practices will be randomised by means of several random lists. These lists include single and group practices and teaching and non-teaching practices, to achieve a roughly equal distribution in both the intervention and the control groups. We chose the stratification factor of (a) single/group practice, because structural characteristic, leadership responsibilities and indicators of psychological wellbeing may differ between practice types $[10,16]$ and (b) teaching/non-teaching practice, as this factor may influence the motivation to participate in the intervention (and may indirectly influence its effects). The randomisation list is generated by an employee of the ZKSE who is not involved in the selection of the practices. Practices will be randomised after baseline data collection, to ensure that study nurses are blinded for the first site visit. The randomisation allocation will be transferred to scientists at the Institute of General Practice and Family Medicine in written form, who will inform the practices by phone and letter. Blinding of the scientists and the practice personnel is not possible due to the participatory concept of the intervention, which includes workshops. Data analysts will follow a predefined protocol for analysis to avoid bias.

\section{Questionnaires and outcome measures}

The primary outcome of this study is an improvement in job satisfaction. To measure job satisfaction, the respective scale of the German version of the Copenhagen Psychosocial Questionnaire based on the international COPSOQ III version (German COPSOQ, version 2018) will be used (www.COPSOQ.de). The COPSOQ is a validated questionnaire that measures psychosocial factors at work [26-28]. The job satisfaction scale of this instrument consists of 6 items (B11: 1-5) and is combined with an additional global item (B11: 7 "how pleased are you with your job as a whole, everything taken into consideration?"). The outcome "ob satisfaction" was selected as the primary outcome, because the IMPROVEjob study evaluates a complex intervention, which addresses various factors known to influence the psychological wellbeing of practice personnel.

The following additional COPSOQ scales will be used as secondary outcomes: quantitative demands (B1: 1, 3, 5), emotional demands (B1: 6-7), work pace (B1: 2, 4), work-privacy conflict (B2: 1-2), and additional items (B2: 3-4, B2: 5) "delimitation" (B2: 6-7), predictability (B6: 1-2), role clarity (B6: $3-5)$, role conflicts (B6: 6-8); social support (B8: 1-4), feedback (B8: 5-6), social relations (B8: 7), sense of community (B8: 8-9) and bullying (B8: 10). To calculate scale scores for each dimension, the COPSOQ will be transformed as recommended [29]. Scales will be transformed into scores ranging from 0 (minimum value, "do not agree at all") to 100 points (maximum value, "fully agree").

The following additional aspects will be addressed using questionnaires: (1) leadership, (2) general health (3) work behaviour, (4) chronic stress, (5) occupational health and safety culture, (6) stress coping strategies applied by participants, (7) work organisational issues including waiting times, team roles and team activities and (8) team activities and roles.

\section{Leadership}

Leadership is assessed with items from the questionnaires on Integrative Leadership (FIF, Fragebogen zur Integrativen Führung) and Leader-Member-Exchange (LMX-7).

The FIF questionnaire [30, 31] focuses on six dimensions of transformational leadership (fostering innovation, team spirit development, performance development, individuality focus, providing a vision, being a role model), two dimensions of transactional leadership (goal setting, management by exception) (module a: items 1-32) [32] and on laissez-faire and destructive leadership (module d: items 65-68) [33]. All items are answered on a 5-point Likert scale. Physicians with leadership responsibilities will assess themselves, whereas other practice physicians and practice assistants will evaluate their leaders. The instrument allows for a comparison of answers provided by leaders and other personnel.

The LMX-7 measures the relationship quality between employees and supervisors (leaders) [34, 35]. It consists of 7 items with 5-point Likert scales. The LMX values are added to a "sum-score. A high score reflects a 
positive assessment of the quality of the relationship with the supervisor. Again, practice owners will assess themselves, while employed practice physicians and practice assistants assess their leaders:

1. General health is assessed using a brief burnout assessment, the World Health Organization-Five Well-Being Index (WHO-5) and the Work Ability Index (WAI).

Burnout is measured using two items from the Maslach Burnout Inventory (emotional exhaustion: "I feel burned out from my work", depersonalization: "I have become more callous toward people since I took this job") [36]. This brief measure of burnout was shown to provide sufficient information on the likelihood of high burnout among physicians and medical students $[37,38]$. The score ranges from $0=$ never to $6=$ every day, and the raw values are processed to obtain a score for emotional exhaustion and depersonalization, which can be compared to the results obtained by the full Maslach Burnout Inventory [38]. Current well-being during the last - 14 days is assessed using the WHO-5 (1998 version) [34, 39]. It consists of 5 items with 6 -point Likert scales $(5=$ all of the time to $0=$ at no time). The scores are added to a sum-score ranging from 0 to 25 and are then multiplied by 4 to give the final score, with 0 denoting the worst and 100 representing the best imaginable wellbeing [34].

Work ability is measured using a single item of the WAI: "personal prognosis of work ability two years from now" on a 3-point Likert scale [40, 41].

2. Work behavior is assessed using short versions of the Occupational Self-Efficacy Scale (BSW, Berufliche Selbstwirksamkeit) and the Work-related Behaviour and Experience Patterns questionnaire (AVEM-44).

Self-efficacy is measured using a short version of the BSW [42]. The instrument consists of 8 items with 6-point Likert scales.

The interplay between work, personality and health is assessed using the short version of the AVEM-44 [43-46]. The AVEM addresses three aspects, which are particularly important for coping with occupational challenges. It consists of 44 items across three domains: professional commitment (20 items across five scales: subjective importance of work; professional ambition; willingness to work to exhaustion; striving for perfection; distancing ability); coping capacity (12 items across three scales: tendency to resign in the face of failure; proactive problemsolving; inner calm and balance); subjective wellbeing (12 items across three scales, experience of success at work; satisfaction with life; experience of social support). Each scale consists of four items, which are measured on a 5-point Likert scale. AVEM identifies four patterns which describe coping strategies for occupational stress: healthyambitious (pattern G), unambitious (pattern S), excessively ambitious (risk pattern A) and burnout (risk pattern B).

3. Chronic stress is measured using the German short version of the Screening Scale of the Trier Inventory for the Assessment of Chronic Stress (TICS-SSCS) [47, 48]. This instrument retrospectively measures strain due to chronic stress, for 3 months. It consists of 12 items on 5point Likert scales ( $0=$ "never" and $4=$ "very often"). The TICS-SSCS values are added to a sum-score. The score ranges from 0 to 48 with 0 denoting "never stressed" and 48 "very often stressed", and reflects subjective strain due to chronic stress.

4. Occupational health and safety is measured using questions from previous studies [49-52], physicians with leadership responsibilities will answer 29 items on occupational safety culture as reported by the practice owners; other staff will answer 28 items.

5. Individual coping strategies are assessed using 26 items specifying various option for stress prevention, e.g. playing an instrument, going for a walk or hiking outdoors and support from friends. Items were derived from previous studies [10].

6. Various issues relating to work organisation will be addressed, e.g. estimated duration and peaks of waiting times for private and non-private patients, working overtime due to problems with organisational workflows, reasons for waiting times.

7. Team activities and roles will be addressed by requesting the frequencies of team sessions and other team activities. Also participants are asked to selfassess their typical personal team role from a choice of nine options.

Socio-demographic characteristics and practice characteristics will be collected as moderating variables. Stable co-variables (e.g. socio-demographic characteristics of study participants, work-related experience and behavioural patterns (AVEM) [53], practice characteristics) will be collected only at baseline, while changeable variables will be measured at both at baseline and follow up. Study nurses will offer an optional workplace safety sheet at baseline, to be completed together with the practice leader. The sheet addresses issues such as hygiene, emergency exits and skin protection instructions. Participation is voluntary for the leaders; a copy of the report will be provided immediately. For an overall schedule see Fig. 2a. 
a. Overall schedule and time commitment for trial participants within the IMPROVEjob intervention including summative and formative assessment

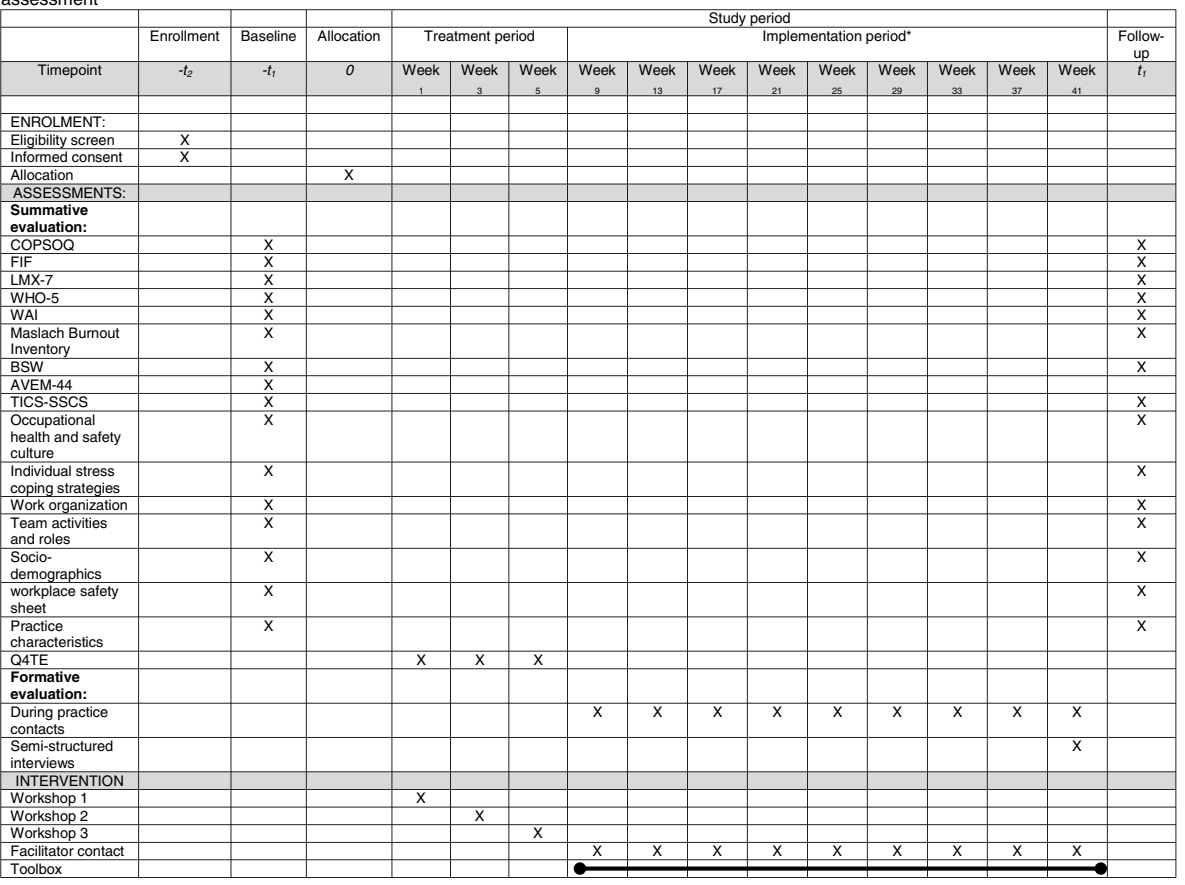

COPSOQ, Copenhagen Psychosocial Questionnaire; FIF, Integrative Leadership; LMX-7, Leader-Member-Exchange; WHO-5,

Health Organization-Five Well-Being Index; WAI, Work Ability Index; BSW, Occupational Self-Efficacy Scale; AVEM-44, Work-related Behaviour and Experience Patterns questionnaire; TICS-SSCS, Trier Inventory for the Assessment of Chronic Stress

* Only for intervention group

b. Summative evaluation: Description of outcomes

\begin{tabular}{|c|c|c|c|c|c|}
\hline Specific measurement & Domain & Metric & $\begin{array}{c}\text { Method of } \\
\text { aggregatio } \\
n\end{array}$ & Time point & Reference \\
\hline COPSOQ* B11 & Job Satisfaction & \multirow{14}{*}{$\begin{array}{l}\text { difference between t1 (= after } 9 \text { months) and } \\
\text { baseline }\end{array}$} & \multirow{14}{*}{$\begin{array}{l}\text { mean } \\
\text { value }\end{array}$} & $-t_{t,} t_{t}$ & \multirow{14}{*}{ [26-29] } \\
\hline \begin{tabular}{|l} 
COPSOQ B1: $1,3,5$ \\
\end{tabular} & Quantitative demands & & & $-t_{1,} t_{1}$ & \\
\hline COPSOQ B1: 6-7 & Emotional demands & & & $-t_{t,} t_{t}$ & \\
\hline COPSOQ B1: 2,4 & Work pace & & & $-t_{1,}, t_{t}$ & \\
\hline COPSOQ B2: 1-2 & Work-privacy conflict & & & $-t_{1,}, t_{1}$ & \\
\hline \begin{tabular}{|l|} 
COPSOQ B2: $3-5$ \\
COPSOQ B2: 6-7
\end{tabular} & $\begin{array}{l}\text { Additional items } \\
\text { Delimitation }\end{array}$ & & & $-t_{1, t}^{-t_{t}}-t_{t}$ & \\
\hline COPSOQ B6: $1-2$ & Predictability & & & $\frac{-t_{1}, t_{t}}{-t_{1} t_{1}}$ & \\
\hline COPSOQ B6: $3-5$ & $\begin{array}{l}\text { Role clarity } \\
\end{array}$ & & & $-t_{1,}, t_{1}$ & \\
\hline COPSOQ B6: $6-8$ & Role conflicts & & & $-t_{1}, t_{1}$ & \\
\hline COPSOQ B8: 1-4 & Social support & & & $-t_{1,} t_{T}$ & \\
\hline COPSOQ B8: 5-6 & feedback & & & $-t_{1,} t_{1}$ & \\
\hline COPSOQ B8: 7 & Social relations & & & $-t_{1}, t_{1}$ & \\
\hline COPSOQ B8: 8-9 & Sense of community & & & $-t_{1,} t_{1}$ & \\
\hline COPSOQ B8: 10 & Bullying & & & $-t_{1,} t_{1}$ & \\
\hline FIF* $^{*}$ & Integrative Leadership & $\begin{array}{l}\text { difference between t1 (= after } 9 \text { months) and } \\
\text { baseline }\end{array}$ & $\begin{array}{l}\text { mean } \\
\text { value }\end{array}$ & $-t_{t,} t_{i}$ & [30-33] \\
\hline \begin{tabular}{|l|l} 
LMX-7* \\
\end{tabular} & Leader-Member-Exchange & $\begin{array}{l}\text { difference between t1 (= after } 9 \text { months) and } \\
\text { baseline }\end{array}$ & $\begin{array}{l}\text { mean } \\
\text { value }\end{array}$ & $-t_{t,} t_{t}$ & {$[34,35]$} \\
\hline WHO-5* & Well-Being & $\begin{array}{l}\text { difference between t1 (= after } 9 \text { months) and } \\
\text { baseline }\end{array}$ & $\begin{array}{l}\text { mean } \\
\text { value }\end{array}$ & $-t_{t}, t_{1}$ & {$[34,39]$} \\
\hline WAl $^{*}$ & Work Ability & $\begin{array}{l}\text { difference between t1 (= after } 9 \text { months) and } \\
\text { baseline }\end{array}$ & $\begin{array}{l}\text { mean } \\
\text { value }\end{array}$ & $-t_{1,} t_{1}$ & {$[40,41]$} \\
\hline \begin{tabular}{|l|} 
Maslach Burnout Inventory \\
\end{tabular} & Burnout & $\begin{array}{l}\begin{array}{l}\text { difference between t1 (= after } 9 \text { months) and } \\
\text { baseline }\end{array} \\
\end{array}$ & $\begin{array}{l}\text { mean } \\
\text { value }\end{array}$ & $-t_{1,} t_{i}$ & [36-38] \\
\hline $\mathrm{BSW}^{*}$ & Occupational Self-Efficacy & $\begin{array}{l}\text { difference between t1 (= after } 9 \text { months) and } \\
\text { baseline }\end{array}$ & $\begin{array}{l}\text { mean } \\
\text { value }\end{array}$ & $-t_{t,} t_{t}$ & [42] \\
\hline AVEM-44* & Work-related Behaviour and Experience & & & Tis & [43-46] \\
\hline \begin{tabular}{|l|} 
TICS-SSCS \\
\end{tabular} & Chronis Stress & $\begin{array}{l}\text { difference between t1 (= after } 9 \text { months) and } \\
\text { baseline }\end{array}$ & $\begin{array}{l}\text { mean } \\
\text { value }\end{array}$ & $-t_{1}, t_{1}$ & {$[47,48]$} \\
\hline $\begin{array}{l}\text { Occupational health and } \\
\text { safety culture }\end{array}$ & Occupational health and safety culture & $\begin{array}{l}\text { difference between t1 (= after } 9 \text { months) and } \\
\text { baseline }\end{array}$ & $\begin{array}{l}\text { mean } \\
\text { value }\end{array}$ & $-t_{t,} t_{t}$ & [49-52] \\
\hline \begin{tabular}{|l|}
$\begin{array}{l}\text { Individual stress coping } \\
\text { strategies }\end{array}$ \\
\end{tabular} & Coping Strategies & $\begin{array}{l}\text { difference between t1 (= after } 9 \text { months) and } \\
\text { baseline }\end{array}$ & $\begin{array}{l}\text { mean } \\
\text { value }\end{array}$ & $-t_{1,} t_{t}$ & [10] \\
\hline Work organisation & Work organisation & $\begin{array}{l}\text { difference between t1 (= after } 9 \text { months) and } \\
\text { baseline }\end{array}$ & $\begin{array}{l}\text { mean } \\
\text { value }\end{array}$ & $-t_{t,}, t_{i}$ & \\
\hline Team activities and roles & Team activities and roles & $\begin{array}{l}\text { difference between t1 (= after } 9 \text { months) and } \\
\text { baseline }\end{array}$ & $\begin{array}{l}\text { mean } \\
\text { value }\end{array}$ & $-t_{1,} t_{i}$ & \\
\hline \begin{tabular}{|l} 
Socio-demographics \\
\end{tabular} & Socio-demographics & & $\begin{array}{c}\text { Mean } \\
\text { value, } \\
\text { frequencie } \\
\mathrm{s}\end{array}$ & $-t_{1}, t_{i}$ & \\
\hline \begin{tabular}{|l|} 
workplace safety sheet \\
\end{tabular} & workplace safety sheet & & & $-t_{1} t_{1}$ & \\
\hline \begin{tabular}{|l} 
Practice characteristics \\
Q4TE \\
\end{tabular} & $\begin{array}{l}\text { Practice characteristics } \\
\text { Workshop Evaluation }\end{array}$ & & & $\frac{-t_{1}, t_{1}}{\text { Week } 1, \text { Week } 3}$ & \\
\hline
\end{tabular}

COPSOQ, Copenhagen Psychosocial Questionnaire; FIF, Integrative Leadership; LMX-7, Leader-Member-Exchange; WHO-5,

Health Organization-Five Well-Being Index; WAI, Work Ability Index; BSW, Occupational Self-Efficacy Scale; AVEM-44, Work-related Behaviour and Experience Patterns questionnaire; TICS-SSCS, Trier Inventory for the Assessment of Chronic Stress

* validated tool

Fig. 2 (See legend on next page.) 
(See figure on previous page.)

Fig. 2 a Overall schedule and time commitment for trial participants within the IMPROVEjob intervention. b Summative evaluation: description of outcomes. COPSOQ, Copenhagen Psychosocial Questionnaire; FIF, Integrative Leadership; LMX-7, Leader-Member-Exchange; WHO-5, Health Organization-Five Well-Being Index; WAI, Work Ability Index; BSW, Occupational Self-Efficacy Scale; AVEM-44, Work-related Behaviour and Experience Patterns questionnaire; TICS-SSCS, Trier Inventory for the Assessment of Chronic Stress

\section{Intervention}

The multimodal participatory intervention was initiated by a general practice physician and researcher (BMW). The intervention was designed cooperatively by researchers from the fields of general practice and family medicine and those from occupational medicine, psychosomatic medicine, operations practice research and workplace health promotion. The intervention focuses on the areas of leadership, work processes and work organization, communication, occupational health and safety and workplace health promotion. It is composed of three elements.

\section{IMPROVEjob workshops}

The intervention begins with a series of three workshops each lasting $4 \mathrm{~h}$. The three workshops will be held within 1 month with 2 -week intervals in between. About 5-6 practices will take part in each workshop depending on the number of staff in each practice. This allows for about 8-10 physicians and 15-25 practice assistants per workshop series. All workshops include presentations by the research team and interactive elements with self-reflection and peer group exchanges.

The specific contents of the workshop are as follows:

1. Workshop 1 for physicians with leadership responsibilities (practice owners and employed physicians with leadership responsibilities): this executive workshop addresses the topics "role of the executive", "leadership styles" and "relational leadership competence" including "transactional and transformational leadership". The workshop includes theoretical inputs delivered via visual presentation, small group interactions, and a skills training session. The later training is designed to allow for training in leadership aspects in a simulated practice scenario with a simulated practice assistant: one participant is asked to take on the role of a physician leader who is facing a conflict between team members with leadership responsibilities. The workshop offers leaders the opportunity to reflect on their own leadership role and values, to increase the awareness for and impact of stress prevention for all team members, and to learn different leadership styles. In particular, different aspects of the relational, transactional and transformational leadership approaches and their effects on employees' health and team-building are addressed.

2. Workshop 2 for physicians with leadership responsibilities and all practice employees: This workshop addresses issues relating to the communication between practice personnel and patients. Using a theoretical framework and interactive skills sessions with trained simulation patients, participants will learn how to analyse encounters with patients that they perceive as challenging and how to better communicate in such situations. Training in challenging situations is provided by drawing on typical scenarios in primary care practices.

3. Workshop 3 for physicians with leadership responsibilities and all practice employees: this workshop addresses issues relating to "work organisation including appointment scheduling", "occupational health and safety" and "workplace health promotion". At the end of the workshop series, practices will be empowered and supported with implementation aids such that they are able to adjust their daily routines according to self-selected goals. Practices will be encouraged to set targets for their implementation phase.

\section{IMPROVEjob toolbox}

The toolbox includes materials presented in the workshops and supplemental material. It comprises two booklets (one for physicians with leadership responsibilities and one for practice employees), a desk calendar and a personal code allowing access to a secured web space with additional material for downloading.

- The "management logbook" (for physicians with leadership responsibilities): this folder contains material for workshops 1-3 plus supplements.

- The "employee logbook" provides materials for workshops 2 and 3 plus supplemental material.

- The desk calendar for practice teams presents a variety of issues from the workshops in a concise card format, e.g. advice on communication with socalled "difficult patients", on occupational health and safety, and on issues of individual health promotion such as relaxation and ergonomics. 
- Supplemental material for download, e.g. practice checklists and other tools, will be provided via a secured webspace. The personalised access allows for the evaluation of webspace use on an individual level.

\section{IMPROVEjob facilitators}

The facilitators are trained members of the research team who will accompany the practices during the change processes by on-site meetings in the practice and/or by phone. Prior to the workshops, the facilitators will be trained in change processes, the setting of GP practices and qualitative data collection in two training sessions. The facilitators concentrate on processes and developments within the practices, but they do not engage in active coaching. They are conceptualised as process companions who remind the practice teams of the project and support the implementation of the intervention. In addition, the facilitators will collect qualitative data in the practices to analyse the relevance, feasibility and implementation of the intervention. The facilitators will take part in the intervention workshops where they will meet the study participants. Also, they will note the practice goals set by each participating practice. After the workshops the facilitators will offer practices to contact them regularly, e.g. once a month, to facilitate the implementation.

\section{Control group}

This study will use a waiting-list control approach. After completion of the follow-up data collection, practices in the control group will be offered the same IMPROVEjob workshops as practices in the intervention group, including access to the toolbox. The project duration and funding does not allow for IMPROVEjob facilitators to be involved in the waiting list control group.

\section{Sample size calculation}

The primary hypothesis of this study is that the IMPROVEjob intervention will have an effect on job satisfaction among personnel working in general practices. The null and alternative hypotheses to be tested are:

$$
\begin{aligned}
& \mathrm{H}_{0}: \mu_{\mathrm{I}}=\mu_{\mathrm{C}} \\
& \mathrm{H}_{\mathrm{A}}: \mu_{\mathrm{I}} \neq \mu_{\mathrm{C}},
\end{aligned}
$$

where $\mu_{\mathrm{I}}$ and $\mu_{\mathrm{C}}$ denote the mean score difference on the COPSOQ job satisfaction scale between baseline and after 9 months, in the intervention arm and in the control arm.

We aim for power of (at least) $80 \%$ with a two-sided significance level $\alpha=0.05$. The calculations will be carried out by means of the clustered $t$ test $[54,55]$, assuming an intra-cluster correlation coefficient (ICC) of 0.05
[56]. All power analyses will be made using the software PASS 13, option "Tests for Two Means in a ClusterRandomized Design".

Assuming a mean value plus/minus standard deviation for the primary endpoint of $73.6 \pm 15$ points [57], we calculate that a sample size of 52 clusters ( 26 practices per arm), each with 3 participating staff members per practice, will be sufficient to detect a change of $10 \%(7.3$ points) with power of $81 \%$ at the chosen significance level. With 4 participants per practice, the power will increase to $89 \%$.

Conversely, with 52 practices and 4 participants per practice, the study would have power of $80 \%$ to detect a change of $0.43 \mathrm{SD}$ in the primary endpoint (and 0.39 SD with 5 participants per practice). This is comparable to the "minimally important difference" (MID) of 0.4 SD proposed as a relevant change in the COPSOQ job satisfaction score [58]. As the values and standard deviation are lower on this scale for physicians than for practice assistants [57, 59], the sample size calculation is rather conservative. Assuming two practice drop-outs in each of the two groups (intervention and control), we will include physicians and practice assistants from 56 general practices in the study.

\section{Data management, statistical analyses and steering committee}

Data management will be carried out by the ZKSE according to standardised procedures as defined in current standard operating procedures (SOPs). The data management system used by the ZKSE has an integrated audit trail and is Good Clinical Practice (GCP)-compliant. Data will be entered by appropriately trained dataentry staff who are familiar with the study specifics. Double data-entry will be used to ensure data quality. Issues of missing data will be addressed by imputation methods according to standard [60]. All personal data will be kept confidential in an access-restricted database. All analyses will be performed using pseudonymised data. The pseudonymised data will be stored at the ZKSE and the Institute of General Practice and Family Medicine of the University of Bonn. The latter institute will manage access to the data set.

Regarding the primary outcome, we hypothesise that the participatory IMPROVEjob intervention will improve job satisfaction among practice personnel. A before-and-after comparison between the intervention and the control group will be used for the evaluation. To control for response shift with respect to job satisfaction, a "then-test" will be applied using a separate sheet to be filled after collection of the follow-up questionnaires [61]. For the statistical analysis, the COPSOQ scales will be transformed according to instrument-specific algorithms [27]. The 
confirmatory analysis to measure the effect of the intervention will be carried out as an intention-totreat analysis, i.e. all participants who completed the job satisfaction scale at baseline and follow up will be included. The primary analysis will be conducted using a linear mixed model adjusted for clustering and the randomisation strata. Per protocol, the analysis will be performed with the data on physicians with leadership responsibility who took part in the management workshop and in at least one of the two team workshops, and with data on practice assistants who took part in at least one team workshop. Additional analyses will focus on secondary outcomes and on associations between various independent and dependent variables. All analyses will respect the cluster-randomised nature of the study design including approaches for analysis of team aspects within the practices. All measures of the summative evaluation will compare mean differences between follow up and baseline (Fig. 2b).

The project is supported by a steering committee with scientists from various fields (general practice and family medicine, occupational psychology, sociology) and representatives of organisations relevant for transfer and dissemination (statutory health insurance, regional medical association, association for health service and welfare work, regional chamber of industry and commerce).

\section{Discussion}

The participatory IMPROVEjob intervention is a novel approach aimed at addressing typical work-related issues encountered in general practices. It is designed to empower teams to analyse their situation and apply selfselected strategies to modify daily work routines. In contrast to many stress-reducing intervention studies [62], our approach integrates behavioural and environmental changes.

Regarding didactics, the IMPROVEjob study applies modern learning strategies such as interactive sessions, peer learning and skills training in leadership and patient-staff communication [63]. The latter allows for a simulation of real-life scenarios and training close to reality following concepts of an enactive mastery experience [64]. The latter was recently shown to be effective in training residents for in-house leadership [65] but has not been evaluated in leadership training for physicians with leadership responsibilities or practice assistants in the outpatient setting.

Given the high prevalence of psychological strain, sick leave due to depression and respective early retirement in various job domains in Germany, the German Federal Ministry of Education and Research has setup the Funding Initiative "Healthy - for life" (in
German, Gesund - ein Leben lang). The IMPROVEjob study is funded within this initiative. Respecting the described societal context, the IMPROVEjob intervention will be evaluated in general practices, which are considered to be models for small and medium sized enterprises, yet - if proven effective - the intervention will be disseminated in other medical settings and evaluated for its transferability to other occupational fields.

\section{Trial status}

This is protocol version \#1. The trial is ongoing. The recruitment of participants started on 5 September 2019 and was completed on 4 March 2020.

\section{Abbreviations \\ AVEM-44: Work-related Behaviour and Experience Patterns questionnaire: BSW: Occupational Self-Efficacy Scale (Berufliche Selbstwirksamkeit); \\ COPSOQ : Copenhagen Psychosocial Questionnaire; FIF: Questionnaires on Integrative Leadership (Fragebogen zur Integrativen Führung); GP: General practitioner; LMX-7: Leader-Member-Exchange; TICS-SSCS: Screening Scale of the Trier Inventory for the Assessment of Chronic Stress; WAl: Work Ability Index; WHO: World Health Organisation; WHO-5: World Health Organization-5 Well-Being Index}

\section{Acknowledgements}

The work of the Institute of Occupational and Social Medicine and Health Services Research is supported by an unrestricted grant from the Employers' Association of the Metal and Electrical Industry Baden-Wuerttemberg (Suedwestmetall). We acknowledge administrative support by the DLR Project Management Agency.

IMPROVEjob consortium

Current institutions and members:

Institute of Occupational and Social Medicine and Health Services Research, University Hospital Tuebingen, Germany: MA Rieger, E Rind, A Siegel, A Wagner, E Tsarouha;

Institute of General Practice and Family Medicine, University Hospital Bonn, Germany: B Weltermann, S Kasten, K Linden, L Degen, A Thielmann;

Department of Psychosomatic Medicine and Psychotherapy, Medical Clinic, University Hospital Tuebingen, Germany: F Junne, T Seifried-Dübon, A. Hermann-Werners, F. Stuber, S Zipfel;

Institute of Management, Operations Research, Ruhr-University Bochum, Germany: B Werners, M Grot;

Institute for Medical Informatics, Biometry and Epidemiology \& Center for Clinical Studies, University of Duisburg-Essen, Germany: K-H Jöckel, C Pieper, V Schröder, J-M Bois, A-L Eilerts, M Brinkmann.

Former institutions and members

Institute for General Medicine, University Hospital Essen, Germany: C Kersting; Institute of Occupational and Social Medicine and Health Services Research University Hospital Tuebingen, Germany: S Emerich, S Burgess, M Hippler; Institute of General Practice and Family Medicine, University Hospital Bonn, Germany: A Dreher;

Institute for Medical Informatics, Biometry and Epidemiology \& Centre for Clinical Trials, University of Duisburg-Essen, Germany: C Ose;

Institute of Management, Operations Research, Ruhr-University Bochum, Germany: L Koppka (Imhoff), J Block.

Authors' contributions

BMW had the study idea and drafted the first version of the manuscript together with SK and KL. All authors contributed to the study protocol and/ or development of the intervention. All authors provided feedback on the manuscript and approved the final version.

\section{Funding}

This study is funded by the German Federal Ministry for Education and Research (grant numbers 01GL1851D, 01GL1751B, 01GL1751A, 01GL1751C). 
The funder had no role in the study design, the data collection and analysis, the decision to publish or the preparation of the manuscript.

\section{Availability of data and materials}

There are no plans to grant access to full protocol, participant-level dataset or statistical code.

\section{Ethics approval and consent to participate}

The study complies with the ethical principles of the World Medical Association Declaration of Helsinki [66]. Ethical approval was obtained from the lead Ethics Committee of the Medical Faculty of the University of Bonn (reference number 057/19, date of approval: 20 February 2019). All participating practice team members will receive written information and sign informed consent forms, which will be stored at the Institute for General Practice and Family Medicine, University of Bonn. In case of modifications of the protocol, relevant parties including the aforementioned ethics committee, will be informed. Authorship will follow the ICMJE recommendations (http://www.icmje.org/recommendations/browse/rolesand-responsibilities/defining-the-roleof-authors-and-contributors.html).

\section{Consent for publication}

Not applicable.

\section{Competing interests}

The authors declare that they have no competing interests.

\section{Author details}

${ }^{1}$ Institute of General Practice and Family Medicine, University Hospital Bonn, University of Bonn, Venusberg-Campus 1, 53127 Bonn, Germany. ${ }^{2}$ Institute for General Medicine, University Hospital Essen, University of Duisburg-Essen, Hufelandstr 55, 45122 Essen, Germany. ${ }^{3}$ Institute for Medical Informatics, Biometry and Epidemiology, University Hospital Essen, University of Duisburg-Essen, Hufelandstr 55, 45147 Essen, Germany. ${ }^{4}$ Department of Psychosomatic Medicine and Psychotherapy, University Hospital Tuebingen, Osianderstraße 5, 72076 Tuebingen, Germany. ${ }^{5}$ Institute of Occupational and Social Medicine and Health Services Research, University Hospital Tuebingen, Wilhelmstr 27, 72074 Tuebingen, Germany. ${ }^{6}$ Center for Clinical Trials, University Hospital Essen, University of Duisburg-Essen, Hufelandstr. 55, 45147 Essen, Germany. ${ }^{7}$ Institute for Operations Research, Ruhr University Bochum, Universitätsstr 150, 44801 Bochum, Germany.

\section{Received: 27 February 2020 Accepted: 16 May 2020}

Published online: 16 June 2020

\section{References}

1. Ahn N, García JR. Job satisfaction in Europe: documento de trabajo 200416: FEDEA; 2004

2. Nicoletti C. Differences in job dissatisfaction across Europe. ISER Working Paper Series, 2006 No. 2006-42. Colchester: University of Essex, Institute for Social and Economic Research (ISER); 2006.

3. Schwartz SA. Trends that will affect your future ... where can I find a family doctor? An unintended consequence of health reform. Explore (NY). 2010;6: 225-6. https://doi.org/10.1016/j.explore.2010.04.007.

4. Le Floch B, Bastiaens H, Le Reste JY, Lingner H, Hoffman R, Czachowski S, et al. Which positive factors give general practitioners job satisfaction and make general practice a rewarding career? A European multicentric qualitative research by the European general practice research network. BMC Fam Pract. 2019;20:1-11. https://doi.org/10.1186/s12875-016-0524-x .

5. Marchand C, Peckham S. Addressing the crisis of GP recruitment and retention: a systematic review. Br J Gen Pract. 2017;67:e227-37. https://doi. org/10.3399/bjgp17X689929

6. Le Floch B, Bastiaens $H$, Le Reste J-Y, Lingner H, Hoffman RD, Czachowski S, et al. Which positive factors determine the GP satisfaction in clinical practice? A systematic literature review. BMC Fam Pract. 2016;17:133. https:// doi.org/10.1186/s12875-016-0524-x

7. van Ham I, Verhoeven AAH, Groenier KH, Groothoff JW, de Haan J. Job satisfaction among general practitioners: a systematic literature review. Eur J Gen Pract. 2006;12:174-80. https://doi.org/10.1080/13814780600994376 .

8. Backé E-M, Seidler A, Latza U, Rossnagel K, Schumann B. The role of psychosocial stress at work for the development of cardiovascular diseases: a systematic review. Int Arch Occup Environ Health. 2012;85:67-79. https:// doi.org/10.1007/s00420-011-0643-6

9. Harvey SB, Modini M, Joyce S, Milligan-Saville JS, Tan L, Mykletun A, et al. Can work make you mentally ill? A systematic meta-review of work-related risk factors for common mental health problems. Occup Environ Med. 2017; 74:301-10. https://doi.org/10.1136/oemed-2016-104015 .

10. Viehmann A, Kersting C, Thielmann A, Weltermann B. Prevalence of chronic stress in general practitioners and practice assistants: personal, practice and regional characteristics. PLoS One. 2017;12:e0176658. https://doi.org/10. 1371/journal.pone.0176658.

11. Wallace JE, Lemaire JB, Ghali WA. Physician wellness: a missing quality indicator. Lancet. 2009;374:1714-21.

12. Khamisa N, Peltzer K, llic D, Oldenburg B. Work related stress, burnout, job satisfaction and general health of nurses: a follow-up study. Int J Nurs Pract. 2016;22:538-45. https://doi.org/10.1111/ijn.12455.

13. Wang J. Work stress as a risk factor for major depressive episode(s). Psychol Med. 2005;35:865-71. https://doi.org/10.1017/s0033291704003241.

14. Theorell T, Tsutsumi A, Hallquist J, Reuterwall C, Hogstedt C, Fredlund P, et al. Decision latitude, job strain, and myocardial infarction: a study of working men in Stockholm. The SHEEP Study Group. Stockholm Heart epidemiology Program. Am J Public Health. 1998;88:382-8. https://doi.org/ 10.2105/AJPH.88.3.382

15. Melchior M, Caspi A, Milne BJ, Danese A, Poulton R, Moffitt TE. Work stress precipitates depression and anxiety in young, working women and men. Psychol Med. 2007;37:1119-29. https://doi.org/10.1017/S0033291707000414

16. Dreher A, Theune M, Kersting C, Geiser F, Weltermann B. Prevalence of burnout among German general practitioners: comparison of physicians working in solo and group practices. PLoS One. 2019;14:e0211223. https:// doi.org/10.1371/journal.pone.0211223 .

17. Goetz K, Broge B, Willms S, Joos S, Szecsenyi J. Job satisfaction of general practitioners. Med Klin (Munich). 2010;105:767-71. https://doi.org/10.1007/ s00063-010-8881-z.

18. Kersting C, Zimmer L, Thielmann A, Weltermann B. Chronic stress, workrelated daily challenges and medicolegal investigations: a cross-sectional study among German general practitioners. BMC Fam Pract. 2019;20:143. https://doi.org/10.1186/s12875-019-1032-6.

19. West CP, Dyrbye LN, Erwin PJ, Shanafelt TD. Interventions to prevent and reduce physician burnout: a systematic review and meta-analysis. Lancet. 2016;388:2272-81. https://doi.org/10.1016/S0140-6736(16)31279-X .

20. Panagioti M, Panagopoulou E, Bower P, Lewith G, Kontopantelis E, ChewGraham C, et al. Controlled interventions to reduce burnout in physicians: a systematic review and meta-analysis. JAMA Intern Med. 2017;177:195-205. https://doi.org/10.1001/jamainternmed.2016.7674

21. Asuero AM, Queraltó JM, Pujol-Ribera E, Berenguera A, Rodriguez-Blanco T, Epstein RM. Effectiveness of a mindfulness education program in primary health care professionals: a pragmatic controlled trial. J Contin Educ Heal Prof. 2014;34:4-12. https://doi.org/10.1002/chp.21211 .

22. Shapiro SL, Brown KW, Biegel GM. Teaching self-care to caregivers: effects of mindfulness-based stress reduction on the mental health of therapists in training. Train Educ Prof Psychol. 2007;1:105. https://doi.org/10.1037/19313918.1.2.105

23. Council of the European Union. Council Directive 89/391/EEC of 12 June 1989 on the introduction of measures to encourage improvements in the safety and health of workers at work: 31989L0391; 1989.

24. Montano D, Hoven $H$, Siegrist J. Effects of organisational-level interventions at work on employees' health: a systematic review. BMC Public Health. 2014; 14:135. https://doi.org/10.1186/1471-2458-14-135 .

25. Viehmann A, Thielmann A, Gesenhues S, Weltermann BM. Do academic family practices reflect routine primary care. (Repräsentieren akademische hausarztpraxen die hausärztliche regelversorgung. Eine methodische Annäherung). Z Allg Med. 2014;90:354-60. https://doi.org/10.1371/journal.pone.0176658 .

26. Nübling M, Stößel U, Hasselhorn HM, Michaelis M, Hofmann F. Measuring psychological stress and strain at work: evaluation of the COPSOQ Questionnaire in Germany. GMS Psychosoc Med. 2006;3:Doc05:1-14. Available at: https://www.egms.de/static/en/journals/psm/2006-3/ psm000025.shtml.

27. Nübling M, Stößel U, Hasselhorn HM, Michaelis M, Hofmann F. Methoden zur Erfassung psychischer Belastungen: erprobung eines messinstrumentes (COPSOQ). (Methods to assess psychologoical strain. Testing a measurement instrument (COPSOQ)). Dortmund/Berlin/Dresden: Wirtschaftsverlag NW; 2005. 
28. Burr $H$, Berthelsen $H$, Moncada $S$, Nübling $M$, Dupret $E$, Demiral $Y$, et al. The third version of the Copenhagen Psychosocial Questionnaire. Saf Health Work. 2019. https://doi.org/10.1016/j.shaw.2019.10.002

29. Nübling M, Hasselhorn HM. The Copenhagen Psychosocial Questionnaire in Germany: from the validation of the instrument to the formation of a jobspecific database of psychosocial factors at work. Scand J Public Health. 2010;38:120-4. https://doi.org/10.1177/1403494809353652 .

30. Rowold J, Poethke U. Fragebogen zur integrativen Führung. FIF. Bern: Hogrefe; 2017

31. Stuber F, Seifried-Duebon T, Rieger MA, Zipfel S, Guendel H, Junne F. Contributors of the SEEGEN Consortium investigating the role of stresspreventive leadership in the workplace hospital: the cross-sectional determination of Relational quality by transformational leadership. Front Psychiatry. 2019. https://doi.org/10.3389/fpsyt.2019.00622

32. Bass BM. Two decades of research and development in transformational leadership. Eur J Work Organ Psychol. 1999;8:9-32.

33. Schyns B, Schilling J. How bad are the effects of bad leaders? A metaanalysis of destructive leadership and its outcomes. Leadersh Q. 2013;24: 138-58. https://doi.org/10.1016/j.leaqua.2012.09.001

34. Topp CW, Østergaard SD, Søndergaard S, Bech P. The WHO-5 Well-Being Index: a systematic review of the literature. Psychother Psychosom. 2015;84: 167-76. https://doi.org/10.1159/000376585 .

35. Graen GB, Uhl-Bien M. Relationship-based approach to leadership: development of leader-member exchange (LMX) theory of leadership over 25 years: applying a multi-level multi-domain perspective. Leadersh Q. 1995; 6:219-47. https://doi.org/10.1016/1048-9843(95)90036-5 .

36. Maslach C, Jackson SE, Leiter MP, Schaufeli WB, Schwab RL. Maslach burnout inventory. Palo Alto: Consulting Psychologists Press; 1986.

37. West CP, Dyrbye LN, Sloan JA, Shanafelt TD. Single item measures of emotional exhaustion and depersonalization are useful for assessing burnout in medical professionals. J Gen Intern Med. 2009;24:1318. https:// doi.org/10.1007/s11606-009-1129-z .

38. West CP, Dyrbye LN, Satele DV, Sloan JA, Shanafelt TD. Concurrent validity of single-item measures of emotional exhaustion and depersonalization in burnout assessment. J Gen Intern Med. 2012;27:1445-52. https://doi.org/10. 1007/s11606-012-2015-7

39. Brähler E, Mühlan H, Albani C, Schmidt S. Teststatistische Prüfung und Normierung der deutschen Versionen des EUROHIS-QOL LebensqualitätIndex und des WHO-5 Wohlbefindens-Index. (Testing and standardization of the German version of the EUROHIS-QOL and WHO-5 quality-of life-indices). Diagnostica. 2007;53:83-96. https://doi.org/10.1026/0012-1924.53.2.83.

40. Hasselhorn HM, Freude G. Der Work Ability Index: Ein Leitfaden. (The work ability index. A guideline). Wirtschaftsverl. NW Verl. für neue Wiss: Bremerhaven; 2007.

41. WAI-Netzwerk am Institut für Sicherheitstechnik. WAI-Manual. https://www. arbeitundbalance.de/downloads/WAl-Manual.pdf. Accessed 28 Nov 2019.

42. Schyns B, von Collani G. A new occupational self-efficacy scale and its relation to personality constructs and organizational variables. Eur J Work Organ Psychol. 2002;11:219-41. https://doi.org/10.1080/13594320244000148

43. Voltmer E, Spahn C, Schaarschmidt U, Kieschke U. Work-related behavior and experience patterns of entrepreneurs compared to teachers and physicians. Int Arch Occup Environ Health. 2011;84:479-90. https://doi.org/ 10.1007/s00420-011-0632-9

44. Braeunig M, Pfeifer $\mathrm{R}$, Schaarschmidt U, Lahmann C, Bauer J. Factors influencing mental health improvements in school teachers. PLoS One. 2018;13:e0206412. https://doi.org/10.1371/journal.pone.0206412.

45. Zimmermann L, Unterbrink T, Pfeifer R, Wirsching M, Rose U, Stößel U, et al. Mental health and patterns of work-related coping behaviour in a German sample of student teachers: a cross-sectional study. Int Arch Occup Environ Health. 2012;85:865-76. https://doi.org/10.1007/s00420-011-0731-7

46. Kieschke U, Schaarschmidt U. Professional commitment and health among teachers in Germany: a typological approach. Learn Instr. 2008;18:429-37. https://doi.org/10.1016/j.learninstruc.2008.06.005

47. Petrowski K, Paul S, Albani C, Brähler E. Factor structure and psychometric properties of the trier inventory for chronic stress (TICS) in a representative German sample. BMC Med Res Methodol. 2012;12:42. https://doi.org/10.1186/1471-2288-12-42

48. Schulz P, Schlotz W, Becker P. Das Trierer Inventar zum chronischen Stress (TICS, Version 3) -Manual. Göttingen: Hogrefe; 2004.

49. Wagner A, Hammer A, Manser T, Martus P, Sturm H, Rieger M. Do Occupational and patient safety culture in hospitals share predictors in the field of psychosocial working conditions? Findings from a cross-sectional study in German university hospitals. Int J Environ Res Public Health. 2018; 15:2131.

50. Wagner A, Rieger MA, Manser T, Sturm H, Hardt J, Martus P, et al. Healthcare professionals' perspectives on working conditions, leadership, and safety climate: a cross-sectional study. BMC Health Serv Res. 2019;19:53. https://doi. org/10.1186/s12913-018-3862-7.

51. Völter-Mahlknecht S, Michaelis M, Preiser C, Blomberg N, Rieger MA. Inanspruchnahme von Angebotsuntersuchungen in der arbeitsmedizinischen Vorsorge: Forschungsbericht 448. (Utilisation of assessments in occupational prevention. Study report 448). Berlin / Bonn: Eigenverlag BMAS; 2015.

52. Lißner L, Brück C, Stautz A, Riedmann A, Strauß A. Abschlussbericht zur 911 Dachevaluation der Gemeinsamen Deutschen Arbeitsschutzstrategie: Kurzfassung. (Final report on the main evaluation of the common German 913 occupational safety strategy-short version). Federal Institute for Occupational Safety and Health. Hamburg, München; 2014.

53. Schaarschmidt $U$, editor. AVEM-ein persönlichkeitsdiagnostisches Instrument für die berufsbezogene Rehabilitation. Bonn: eutscher Psychologen Verlag GmbH; 2006.

54. Donner A, Klar N. Statistical considerations in the design and analysis of community intervention trials. J Clin Epidemiol. 1996;49:435-9.

55. Donner A, Klar N, Klar NS. Design and analysis of cluster randomization trials in health research. London: Arnold London; 2000.

56. Campbell MK, Mollison J, Steen N, Grimshaw JM, Eccles M. Analysis of cluster randomized trials in primary care: a practical approach. Fam Pract. 2000;17:192-6. https://doi.org/10.1093/fampra/17.2.192

57. Goetz K, Berger S, Gavartina A, Zaroti S, Szecsenyi J. How psychosocial factors affect well-being of practice assistants at work in general medical care?-A questionnaire survey. BMC Fam Pract. 2015;16:166. https://doi.org/ 10.1186/s12875-015-0366-y.

58. Pejtersen $\mathrm{JH}$, Bjorner JB, Hasle P. Determining minimally important score differences in scales of the Copenhagen Psychosocial Questionnaire. Scand J Public Health. 2010;38:33-41. https://doi.org/10.1177/1403494809347024

59. Sturm H, Ueding E, Wagner A, Hammer A, Martus P, Manser T, Rieger MA. WorkSafeMed-Arbeitsbedingungen, Sicherheitskultur und Patientensicherheit in Krankenhäusern-welche Prädiktoren lassen sich für die Sicherheit des Medikationsprozesses beschreiben?: Schlussbericht des BMBF-Verbundprojekts WorkSafeMed. (WorkSafeMEd-working conditions, safety culture and patient safety in hospitals-which predictors can be described for the safety of the medication process? Final report of the BMBF projekt WorkSafeMed): Eberhard-Karls-Universität Tübingen - Institut für Arbeitsmedizin, Sozialmedizin und Versorgungsforschung, Universitätsklinikum Tübingen; 2017.

60. Fiero MH, Huang S, Oren E, Bell ML. Statistical analysis and handling of missing data in cluster randomized trials: a systematic review. Trials. 2016; 17(1):72.

61. Nolte S, Elsworth GR, Sinclair AJ, Osborne RH. The inclusion of 'then-test' questions in post-test questionnaires alters post-test responses: a randomized study of bias in health program evaluation. Qual Life Res. 2012; 21:487-94. https://doi.org/10.1007/s11136-011-9952-1

62. Giga SI, Fletcher IJ, Sgourakis G, Mulvaney CA, Vrkljan BH. Organisational level interventions for reducing occupational stress in healthcare workers. Cochrane Database Syst Rev. 2018. https://doi.org/10.1002/14651858. CD013014

63. Frich JC, Brewster AL, Cherlin EJ, Bradley EH. Leadership development programs for physicians: a systematic review. J Gen Intern Med. 2015;30: 656-74. https://doi.org/10.1007/s11606-014-3141-1

64. Bandura A. Self-efficacy: the exercise of control. New York: W.H. Freeman and Company; 1997.

65. Saravo B, Netzel J, Kiesewetter J. The need for strong clinical leaderstransformational and transactional leadership as a framework for resident leadership training. PLoS One. 2017;12:e0183019. https://doi.org/10.1371/ journal.pone.0183019

66. Citation should be changed to: World Medical Association. World Medical Association Declaration of Helsinki: ethical principles for medical research involving human subjects. J Postgrad Med. 2002;48(3):206-8.

\section{Publisher's Note}

Springer Nature remains neutral with regard to jurisdictional claims in published maps and institutional affiliations. 